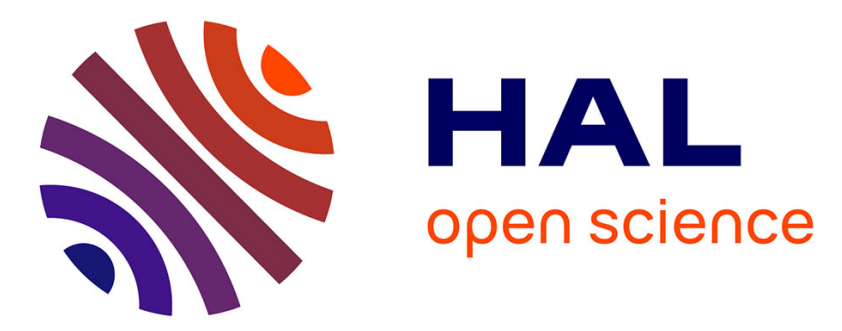

\title{
Influence of structural changes on photophysical properties of terpyridine derivates: Experimental studies and theoretical calculations
}

\author{
D. Toledo, F. Brovelli, J. Soto-Delgado, O. Peña, J.-Y. Pivan, Y. Moreno
}

\section{- To cite this version:}

D. Toledo, F. Brovelli, J. Soto-Delgado, O. Peña, J.-Y. Pivan, et al.. Influence of structural changes on photophysical properties of terpyridine derivates: Experimental studies and theoretical calculations. Journal of Molecular Structure, 2018, 1153, pp.282-291. 10.1016/j.molstruc.2017.10.011 . hal01639696

\section{HAL Id: hal-01639696 \\ https://hal-univ-rennes1.archives-ouvertes.fr/hal-01639696}

Submitted on 6 Dec 2017

HAL is a multi-disciplinary open access archive for the deposit and dissemination of scientific research documents, whether they are published or not. The documents may come from teaching and research institutions in France or abroad, or from public or private research centers.
L'archive ouverte pluridisciplinaire HAL, est destinée au dépôt et à la diffusion de documents scientifiques de niveau recherche, publiés ou non, émanant des établissements d'enseignement et de recherche français ou étrangers, des laboratoires publics ou privés. 


\section{Accepted Manuscript}

Influence of structural changes on photophysical properties of terpyridine derivates:

Experimental studies and theoretical calculations

Dominique Toledo, Francisco Brovelli, Jorge Soto-Delgado, Octavio Peña, Jean-Yves

Pivan, Yanko Moreno

PII: $\quad$ S0022-2860(17)31342-X

DOI: $\quad$ 10.1016/j.molstruc.2017.10.011

Reference: MOLSTR 24382

To appear in: Journal of Molecular Structure

Received Date: 22 July 2017

Revised Date: 8 September 2017

Accepted Date: 2 October 2017

Please cite this article as: D. Toledo, F. Brovelli, J. Soto-Delgado, O. Peña, J.-Y. Pivan, Y. Moreno, Influence of structural changes on photophysical properties of terpyridine derivates:

Experimental studies and theoretical calculations, Journal of Molecular Structure (2017), doi: 10.1016/ j.molstruc.2017.10.011.

This is a PDF file of an unedited manuscript that has been accepted for publication. As a service to our customers we are providing this early version of the manuscript. The manuscript will undergo copyediting, typesetting, and review of the resulting proof before it is published in its final form. Please note that during the production process errors may be discovered which could affect the content, and all legal disclaimers that apply to the journal pertain. 
Influence of structural changes on photophysical properties of terpyridine derivates: experimental studies and theoretical calculations.

Dominique Toledo, Francisco Brovelli, Jorge Soto-Delgado, Octavio Peña, Jean-Yves Pivan, Yanko Moreno*
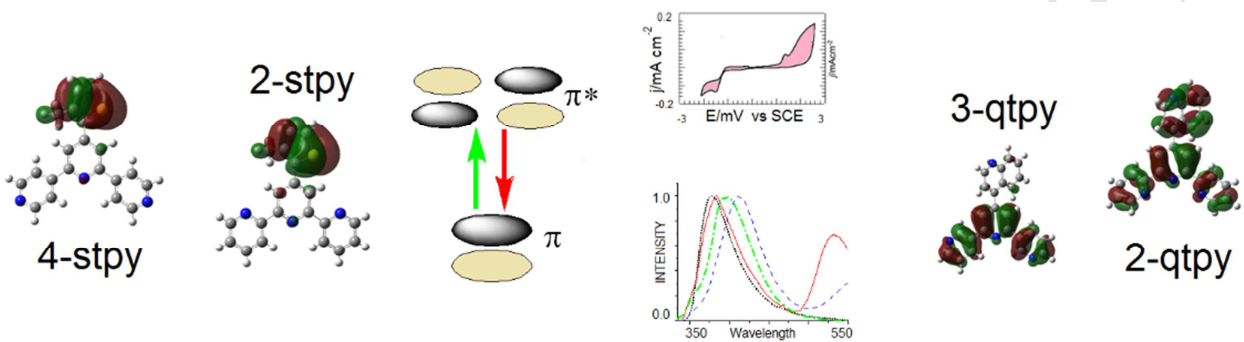

Four terpyridine ligands containing different aryl substituents have been studied, relating their structure with their physical properties. 


\section{Influence of structural changes on photophysical properties of terpyridine derivates: experimental studies and theoretical calculations.}

Dominique Toledo, ${ }^{1}$ Francisco Brovelli, ${ }^{2}$ Jorge Soto-Delgado, ${ }^{3}$ Octavio Peña, ${ }^{4}$ Jean-Yves Pivan, ${ }^{4,5}$ Yanko Moreno $*^{3}$

1 Departamento de Química Analítica e Inorgánica, Facultad de Ciencias Químicas, Universidad de Concepción, Concepción, Chile.

2 Departamento Ciencias Básicas, Escuela de Educación, Campus Los Ángeles, Universidad de Concepción, Chile

${ }^{3}$ Universidad Andrés Bello, Departamento de Química, Facultad de Ciencias Exactas, PC 2520000, Viña del Mar, Chile.

${ }^{4}$ Institut des Sciences Chimiques de Rennes, UMR 6226, Université de Rennes-1, Rennes, France

${ }^{5}$ École Nationale Supérieure de Chimie de Rennes, Rennes, France

*: Corresponding author: yanko.moreno@unab.cl 


\begin{abstract}
Four terpyridine ligands containing different aryl substituents 4'-(4-quinolinyl)-3,2':6',3"terpyridine (3-qtpy), 4'-(4-quinolinyl)-2,2':6',2"-terpyridine (2-qtpy), 4'-(3-methyl-2thienyl)-4,2':6',4"-terpyridine (4-stpy) and 4'-(3-methyl-2-thienyl)-2,2':6',2"-terpyridine (2stpy) were synthesized in a one-pot procedure and characterized by elemental analysis, FTIR and ${ }^{1} \mathrm{H}$ - and ${ }^{13} \mathrm{C}-\mathrm{NMR}$ spectroscopy. Additionally, the 2-stpy structure was confirmed by single crystal X-ray diffraction analysis.

The influence of the N-position in the tpy and aryl substituents on the photophysical properties was systematically investigated by spectroscopic methods and simulated by density functional theory (DFT and TD-DFT) calculations.

Thermal stability was observed until about $280^{\circ} \mathrm{C}$, making these kind of ligands interesting candidates for their use as complex ligands, which are obtained by solvothermal synthesis under temperatures of about $180^{\circ} \mathrm{C}$.

The electrochemical behaviour was also investigated. All molecules show irreversible anodic and cathodic voltammetric peaks in organic medium.
\end{abstract}




\section{Introduction}

Systems such as polypyridine ligands have received significant attention in recent years, as building blocks in coordination polymers and networks. ${ }^{1-3}$ It is always very interesting in coordination chemistry to have a molecular system able to coordinate hard and soft metal ions forming stable systems, with potential applications in supramolecular chemistry, gas adsorption, molecular electronics, catalysis, magnetism, luminescence, light-harvesting complexes for dye sensitized solar cells, etc. ${ }^{4-12}$

In the search of molecular systems formed with multidentate ligands containing N-donor heterocyclic rings, terpyridine derivatives have attracted our interest as good candidates to be used as building blocks for preparation of coordination polymers and related functional materials. $^{13-15}$

Along the years, n,2':6',n" Terpyridines (tpy) as well as all their 4'-substituted derivatives have been subject of intensive structural study, in any of their current forms, viz., $n, n "=2$, 3 and 4 (Scheme 1).

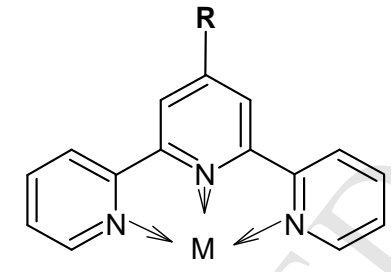

2,2':6',2"-terpyridine ( 2-tpy)

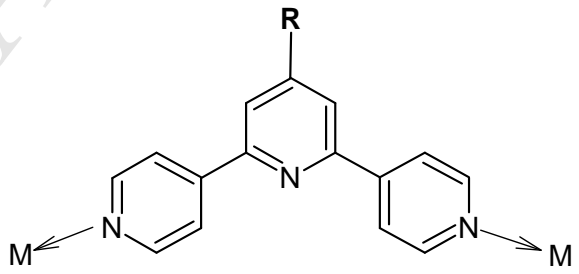

4,2':6',4"-terpyridine ( 4-tpy)<smiles>[R]c1cc(-c2ccc[n+]([M])c2)nc(-c2ccc[n+]([M])c2)c1</smiles>
3,2':6',3"-terpyridine ( 3-tpy)

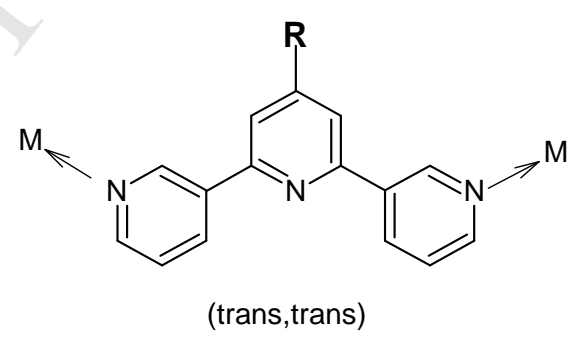

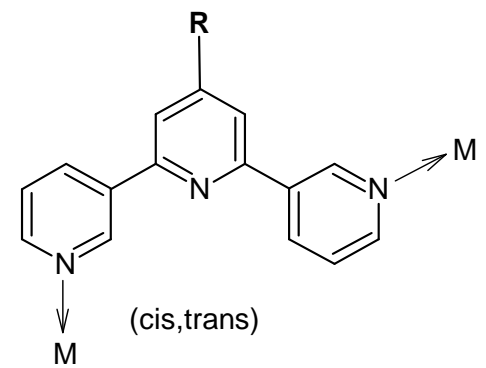

Scheme 1. 4'-substituted- 2,2':6',2', 3,2':6',3'” and 4,2':6',4'-terpyridine ligands and their possible coordination modes.

The design and characteristic features of these bridging ligands, such as rigidity or flexibility, thermal and chemical stability, introduction of 4'-substituents, R, and the 
different spatial disposition of the $\mathrm{N}$-donor atoms, play an important role in the topology of the resulting coordination compounds, which includes a wide variety of one-, two-, threedimensional and also discrete supramolecular structures. ${ }^{14,16-19}$

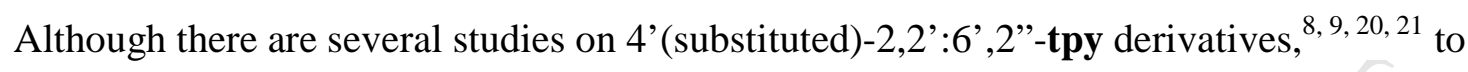
the best of our knowledge, the influence on the photophysical properties of both aryl substituents and the N-position in the terpyridine remains mostly unexplored.

Motivated by this, we describe heirein the synthetic route (Scheme 2), the thermal stability, the photophysical and electrochemical properties of four 4-(substituted)-terpyridine ligands: 4'-(4-quinolinyl)-3,2':6',3"-terpyridine (3-qtpy), 4'-(4-quinolinyl)-2,2':6',2"-terpyridine (2qtpy), 4'-(3-methyl-2-thienyl)-4,2':6',4"-terpyridine (4-stpy) and 4'-(3-methyl-2-thienyl)2,2':6',2"-terpyridine (2-stpy) (Scheme 3). These ligands are thermally stable up to about $280^{\circ} \mathrm{C}$, then the solvothermal synthesis to obtain coordination compounds can also be implemented. In addition to their spectroscopic data, crystals of the 2-stpy ligand were obtained and its structure was confirmed by single crystal X-ray diffraction analysis.

The influence of the $\mathrm{N}$-position in the tpy and aryl substituents on the photophysical properties of these compounds is systematically discussed by spectroscopic methods and simulated by density functional theory (DFT and TD-DFT) calculations.

2<smiles>CC(=O)c1c[X][c]cc1</smiles>

$\mathrm{X}=\mathrm{N} ; \mathrm{Y}=\mathrm{C} ; \mathrm{Z}=\mathrm{C}$

$\mathrm{X}=\mathrm{C} ; \mathrm{Y}=\mathrm{N} ; \mathrm{Z}=\mathrm{C}$

$\mathrm{X}=\mathrm{C} ; \mathrm{Y}=\mathrm{C} ; \mathrm{Z}=\mathrm{N}$ i) EtOH/PEG-300, $\mathrm{KOH}$

ii) $\mathrm{NH}_{3}$<smiles>[Y][X]c1cc[Z](-c2cc([Al])cc(-c3cc[Z]([H])cc3)n2)cc1</smiles>

Ar:

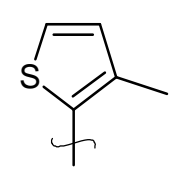

$\mathbf{S}$<smiles>Clc1ccnc2ccccc12</smiles>

q

Scheme 2. Synthetic route for terpyridine ligands. 


\section{Experimental}

\section{1- General Experimental Methods}

The terpyridine systems were prepared according to the Aldol condensation and Michael addition methods. ${ }^{22,23}$ All chemical reagents were used without further purification.

4-stpy and 3-qtpy have been prepared as previously reported. ${ }^{15,}{ }^{24}$ Microanalyses were recorded on a Thermo-FINNIGAN Flash EA 1112 CHNS/O analyzer at the Microanalytical Service of the CRMPO at the University of Rennes 1, France. NMR spectroscopy: ${ }^{1} \mathrm{H}$ and ${ }^{13} \mathrm{C}$ NMR spectra in $\mathrm{CDCl}_{3}$ solution were recorded on a Bruker-400 NMR spectrometer (chemical shifts referenced to residual solvent peaks, $\delta$ TMS $=0$ ). FT-IR spectra were obtained using $\mathrm{KBr}$ pellets on a Bruker EQUINOX 55 Fourier transform infrared spectrometer in the $400-4000 \mathrm{~cm}^{-1}$ region. UV-Vis absorption spectra were recorded in $\mathrm{CH}_{2} \mathrm{Cl}_{2}$ solutions on an Agilent 8453 Diode-Array spectrophotometer in the range of 200-800 nm. Emission spectra, both in $\mathrm{CH}_{2} \mathrm{Cl}_{2}$ solutions and solid state, were measured in a Horiba Jobin-Yvon FluoroMax-4 spectrofluorometer at room temperature. Thermogravimetric analyses (TGA) were carried out using a SDT Q600 V20.9 Build 20 (TA instruments) at a rate of $10^{\circ} \mathrm{C} / \mathrm{min}$ in a nitrogen atmosphere. Cyclic voltammetry (CV) measurements were carried out using experimental setups as previously described. ${ }^{25}$ The electrochemical experiments were performed in a Wavenow USB potentiostat/galvanostat (PINE research instruments, USA): a glassy carbon electrode (GCE) of $0.28 \mathrm{~cm}^{2}$ geometric area was used as working electrode. The reference electrode was $\mathrm{Ag} / \mathrm{AgCl}$ in tetraethylammonium chloride-dichlormethane solution whose potential was adjusted with respect to a saturated calomel electrode (SCE). ${ }^{26}$ A platinum coil was used as auxiliary electrode, in a separated compartment from the working electrode.

Computational details. DFT calculations were carried out using the B3LYP/ 6-31+G(d) level of theory. Ground states were fully optimized without symmetry restrictions, and vibrational frequencies were obtained in order to ensure that optimized structures correspond to energy minimum, obtaining only positive frequencies. At the TD-DFT methodology was performed at the same level of theory they singlet excited states were obtained to account for the characteristics of the experimental UV-Vis spectrum. For NMR calculation, the geometry optimization was carried out using the mPW1PW91/6-31G(d) level of theory. The ${ }^{13} \mathrm{C}$ NMR chemical shift were calculated using GIAO (Gauge Invariant 
Atomic Orbitals) method using a mPW1PW91/6-31G(d,p) level of theory. In all calculations, the solvent effects were incorporated through the polarizable continuum model (PCM) with an integral equation formalism variant (IEFPCM) with UFF radii. ${ }^{27}$ All calculations were performed in the Gaussian 09 program. $^{28}$

\subsection{Synthesis of terpyridine ligands}
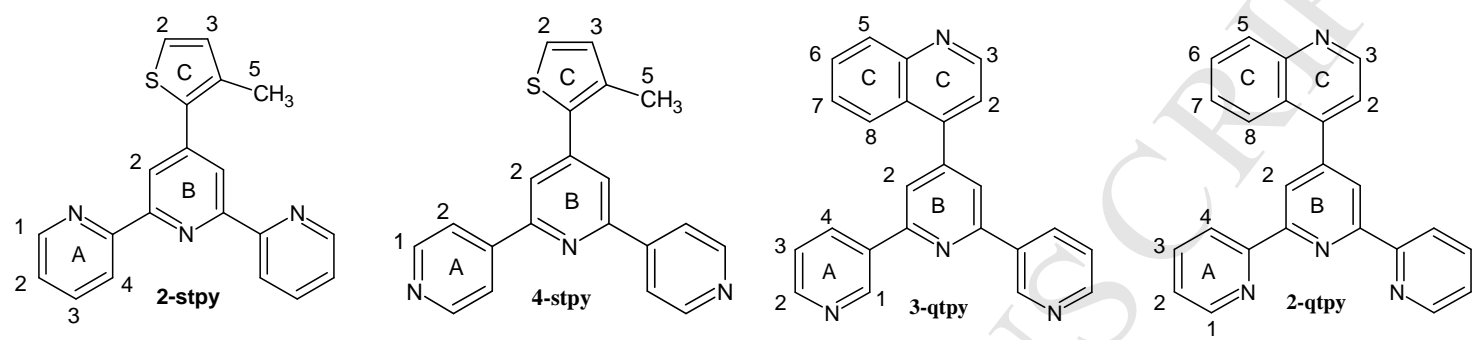

Scheme 3. Terpyridine ligands, presenting the atomic labelling for NMR spectroscopic assignements.

\section{General Procedure}

\section{4'-(3-methyl-2-thienyl-)-2,2':6',2'-terpyridine.- (2-stpy)}

The synthesis of 2-spty has been reported elsewhere. ${ }^{29}$ We describe in the following, an alternative and higher yielding route, fully assigned by spectroscopic methods; the crystal structure is reported here for the first time. 2-acetylpyridine $(2.24 \mathrm{~g}, 20 \mathrm{mmol})$ was added to a stirred suspension of crushed $\mathrm{KOH}(1.12 \mathrm{~g}, 20 \mathrm{mmol})$ in PEG-300 $(30 \mathrm{~mL})$ at $0{ }^{\circ} \mathrm{C}$. After $30 \mathrm{~min}$ the corresponding aldehyde $(10 \mathrm{mmol})$ was added and the reaction mixture was kept stirring at $0{ }^{\circ} \mathrm{C}$ for $2 \mathrm{~h}$. Then $\mathrm{NH}_{4} \mathrm{OH}(25 \mathrm{~mL})$ was added and the suspension was heated at $80{ }^{\circ} \mathrm{C}$ overnight. During this time, the product formed a brown precipitate. The product was filtered off, washed with cold $\mathrm{EtOH}(10 \mathrm{~mL})$ and recrystallized in $\mathrm{CHCl}_{3}$. After two days it yielded yellowish blocks suitable for single crystal X-ray analysis. $\mathrm{C}_{20} \mathrm{H}_{15} \mathrm{~N}_{3} \mathrm{~S}(1390 \mathrm{mg}$, 4.22 mmol, 42.2 \%). Anal, Calc: C, 72.92; H, 4.59; N, 12.76; S, 9.73. Found: C, 71.71; H, 4.47; N, 12.49; S, 9.57. ${ }^{1} \mathbf{H}$ NMR (400 MHz, $\left.\mathrm{CDCl}_{3}\right) \delta 8.74\left(\mathrm{~d}, \mathrm{~J}=4.0 \mathrm{~Hz}, 2 \mathrm{H}, \mathrm{H}^{\mathrm{Al}}\right), 8.67$ $\left(\mathrm{d}, \mathrm{J}=7.6 \mathrm{~Hz}, 2 \mathrm{H}, \mathrm{H}^{\mathrm{A} 4}\right), 8.61\left(\mathrm{~s}, 1 \mathrm{H}, \mathrm{H}^{\mathrm{B} 2}\right), 7.90\left(\mathrm{td}, \mathrm{J}=8.0,4.0 \mathrm{~Hz}, 2 \mathrm{H} . \mathrm{H}^{\mathrm{A} 3}\right), 7.43-7.30$ $\left(\mathrm{m}, 3 \mathrm{H}, \mathrm{H}^{\mathrm{A} 2+\mathrm{C} 2}\right), 6.98\left(\mathrm{~d}, \mathrm{~J}=4.8 \mathrm{~Hz}, 1 \mathrm{H}, \mathrm{H}^{\mathrm{C} 3}\right), 2.52\left(\mathrm{~s}, 3 \mathrm{H}, \mathrm{H}^{\mathrm{C} 5}\right) .{ }^{13} \mathbf{C}$ NMR $(101 \mathrm{MHz}$, $\left.\mathrm{CDCl}_{3}\right) \delta 155.90\left(\mathrm{C}^{\mathrm{A} 5}\right), 155.52\left(\mathrm{C}^{\mathrm{B} 1}\right), 149.03\left(\mathrm{C}^{\mathrm{A} 1}\right), 144.81\left(\mathrm{C}^{\mathrm{B} 3}\right), 137.38\left(\mathrm{C}^{\mathrm{A} 3}\right), 136.02$ $\left(\mathrm{C}^{\mathrm{C} 1}\right), 135.43\left(\mathrm{C}^{\mathrm{C} 4}\right), 131.79\left(\mathrm{C}^{\mathrm{C} 3}\right), 125.35\left(\mathrm{C}^{\mathrm{C} 2}\right), 124.07\left(\mathrm{C}^{\mathrm{A} 2}\right), 121.66\left(\mathrm{C}^{\mathrm{A} 4}\right), 120.68\left(\mathrm{C}^{\mathrm{B} 2}\right)$, $15.73\left(\mathrm{C}^{\mathrm{C} 5}\right)$. FT-IR $\left(\mathrm{KBr}, \mathrm{cm}^{-1}\right) 3054(\mathrm{~m}), 3005(\mathrm{w})$ (merged $v_{\mathrm{CH}}$ pyridine and thiophene 
rings), 2962(w), $2925(\mathrm{w}), 2868(\mathrm{w})$ ( $\mathrm{v}_{\mathrm{CH}}$ methyl), 1576(s), 1556(s), 1460(s), 1398(s) (v $\mathrm{v}_{\mathrm{CC}}$ pyridine and thiophene rings), 1259 (w), 881(w), 785(s), 731(s), $656(\mathrm{~m})$.

\section{4'-(4-quinolinyl)-2,2' :6' ,2' '-terpyridine (2-qtpy).}

2-acetylpyridine (2.42 g, $20.0 \mathrm{mmol})$ was added to $20 \mathrm{~mL}$ of 4-quinolinylcarboxaldehyde ethanolic solution (1.56 g, $10 \mathrm{mmol})$. The solution was stirred for $10 \mathrm{~min}$, then $\mathrm{KOH}$ (1.12 g, $20 \mathrm{mmol})$ and $\mathrm{NH}_{4} \mathrm{OH}(29 \mathrm{~mL})$ were added. The mixture was stirred for $13 \mathrm{~h}$. A white precipitate was obtained and then filtered and washed with cold ethanol $(2 \times 15 \mathrm{~mL})$. Recrystallization of the ligand was done in $\mathrm{CHCl}_{3}(18 \mathrm{~mL})$. 2-qtpy was isolated as a white solid $\mathrm{C}_{24} \mathrm{H}_{16} \mathrm{~N}_{4}$ (1764 mg, 4.89 mmol, 48.9\%). Anal, Calc: C, 79.98; H, 4.47; N, 15.54. Found: C, 79.94; H, 4.65; N, 15.60. ${ }^{1} \mathbf{H}$ NMR $\left(400 \mathrm{MHz}, \mathrm{CDCl}_{3}\right) \delta 9.03(\mathrm{~d}, \mathrm{~J}=4.6 \mathrm{~Hz}, 1 \mathrm{H}$, $\left.\mathrm{H}^{\mathrm{C} 3}\right), 8.73\left(\mathrm{~d}, \mathrm{~J}=8.0 \mathrm{~Hz}, 2 \mathrm{H}, \mathrm{H}^{\mathrm{A} 1}\right), 8.70\left(\mathrm{~d}, \mathrm{~J}=4.4 \mathrm{~Hz}, 2 \mathrm{H}, \mathrm{H}^{\mathrm{A} 4}\right), 8.67\left(\mathrm{~s}, 1 \mathrm{H}, \mathrm{H}^{\mathrm{B} 2}\right), 8.37$ $\left(\mathrm{d}, \mathrm{J}=8.5 \mathrm{~Hz}, 1 \mathrm{H}, \mathrm{H}^{\mathrm{C} 5}\right), 8.00\left(\mathrm{~d}, \mathrm{~J}=7.6 \mathrm{~Hz}, 1 \mathrm{H}, \mathrm{H}^{\mathrm{C} 8}\right), 7.92\left(\mathrm{td}, \mathrm{J}=6.4,4.0 \mathrm{~Hz}, 2 \mathrm{H}, \mathrm{H}^{\mathrm{A} 3}\right)$, $7.83\left(\mathrm{t}, \mathrm{J}=7.7 \mathrm{~Hz}, 1 \mathrm{H}, \mathrm{H}^{\mathrm{C} 6}\right), 7.60\left(\mathrm{~m}, 2 \mathrm{H}, \mathrm{H}^{\mathrm{C} 7+\mathrm{C} 2}\right), 7.37\left(\mathrm{t}, \mathrm{J}=6.0 \mathrm{~Hz}, 2 \mathrm{H}, \mathrm{H}^{\mathrm{A} 2}\right) .{ }^{13} \mathbf{C} \mathbf{N M R}$ $\left(101 \mathrm{MHz} \mathrm{CDCl}_{3}\right) \delta 156.12\left(\mathrm{C}^{\mathrm{A} 5}\right), 155.71\left(\mathrm{C}^{\mathrm{B} 1}\right), 149.39\left(\mathrm{C}^{\mathrm{A} 1}\right), 148.60\left(\mathrm{C}^{\mathrm{C} 3}\right), 148.26\left(\mathrm{C}^{\mathrm{C} 4}\right)$, $147.52\left(\mathrm{C}^{\mathrm{C} 9}\right), 146.93\left(\mathrm{C}^{\mathrm{B} 3}\right), 137.21\left(\mathrm{C}^{\mathrm{A} 3}\right), 130.73\left(\mathrm{C}^{\mathrm{C} 6}\right), 128.80\left(\mathrm{C}^{\mathrm{C} 5}\right), 128.04\left(\mathrm{C}^{\mathrm{C} 7, \mathrm{C}^{2}}\right)$, $126.32\left(\mathrm{C}^{\mathrm{C} 1}\right), 125.75\left(\mathrm{C}^{\mathrm{C} 8}\right), 124.36\left(\mathrm{C}^{\mathrm{A} 2}\right), 121.60\left(\mathrm{C}^{\mathrm{B} 2}\right), 121.55\left(\mathrm{C}^{\mathrm{A} 4}\right), 121.26\left(\mathrm{C}^{\mathrm{C} 7, \mathrm{C} 2}\right)$.

FT-IR $\left(\mathrm{KBr}, \mathrm{cm}^{-1}\right)$ 3054(w) $3006(\mathrm{w})$ (merged $v_{\mathrm{CH}}$ pyridine and quinoline rings) 1574(s) 1554(s) 1466(m) 1392(m) ( $\mathrm{CCC}$ and $/ \mathrm{CN}$ pyridine and quinoline rings); $1124(\mathrm{~m}), 993(\mathrm{w})$, 846(w) 785(s), 624(m).

\subsection{Crystal structure determination}

Crystal data were collected on a Bruker SMART AXS CCD diffractometer with graphitemonochromated Mo $\mathrm{K}_{\alpha}$ radiation $(\lambda=0.71073 \AA)$. The structures were solved by direct methods and refined by full-matrix least squares on $F^{2}(S H E L X L-2014)^{30}$ with the aid of the Olex2 program. ${ }^{31}$ All non-hydrogen atoms were refined anisotropically. $\mathrm{H}$ atoms were finally included in their calculated positions. A final refinement on $F^{2}$ with 3264 unique intensities and 208 parameters converged at $\omega R\left(F^{2}\right)=0.1498(R(F)=0.0525)$ for 2564 observed reflections with $I>2 \sigma(I)$. The structural analysis was performed with the help of the multipurpose PLATON. ${ }^{32}$ 
A summary of the details about crystal data collection parameters and refinement are documented in Table S1. Additional crystallographic details are in the CIF files. ORTEP views and the molecular representations shown in the figures were generated using Olex2. ${ }^{31}$

\section{Results and Discussion}

\subsection{Synthesis and characterization}

The terpyridine ligands were obtained in moderate yield (40-50\%) following the synthetic route described in Scheme 2. Different aryl substituents are incorporated into the 4'position of the tpy moiety. 4-stpy and 3-qtpy were prepared as previously reported. ${ }^{15,19}$

The 2-stpy ligand has previously been prepared by Srodoba et al, ${ }^{29}$ with a $8.5 \%$ yield using a procedure based on the two-step Kröhnke methodology. ${ }^{33}$ We found that an improved yield of $42.2 \%$ of 2-stpy could be obtained by one-pot method under environmentally friendly reaction conditions using PEG and aqueous ammonia as solvents. ${ }^{23}$ In their work, authors characterized 2-stpy only by elemental analysis, IR and NMR spectroscopy. ${ }^{29}$ Here, in addition to their spectroscopic data, the structure of 2-stpy is confirmed by single crystal $\mathrm{X}$-ray diffraction.

All terpyridine ligands were separated as air-stable solids and fully characterized by elemental analysis, spectrometric (IR, NMR and UV-Vis), TGA and electrochemical measurements.

These terpyridine ligands have characteristic fundamental vibrational modes and in most cases the corresponding bands can be easily identified. FT-IR computed and experimental spectra for tpy ligands are shown in Fig. S1-S4. The bands observed near $3400 \mathrm{~cm}^{-1}$ was originated from the wet $\mathrm{KBr}$ matrix. The bands observed in $3200-3000 \mathrm{~cm}^{-1}$ region were attributed to the unsaturated $v \mathrm{CH}$ stretching vibration mode of the aromatics rings.

For 2-stpy and 4-stpy three weak bands at 2962, 2930 and $2867 \mathrm{~cm}^{-1}$ were also observed due to the $v \mathrm{CH}$ stretching vibration of the aliphatic moiety $\left(-\mathrm{CH}_{3}\right)$.

Additionally, all spectra exhibit a series of bands between $1600-1300 \mathrm{~cm}^{-1}$ indicating the presence of the $v(\mathrm{C} \cdots \mathrm{O}), v(\mathrm{C} \cdots \mathrm{C})$ and $v(\mathrm{C} \cdots \mathrm{N})$ bonds. ${ }^{34}$

Besides, the thienyl moiety in 2-stpy and 4-stpy was confirmed due to the presence of strong bands at 785 and $731 \mathrm{~cm}^{-1}$ and attributed to the out of plane bending vibration mode of the $\mathrm{C}-\mathrm{H}$ groups present in this ligand..$^{35,36}$ 
The theoretical computed IR frequencies for all tpy ligands are listed in Table S2 with the experimentally determined frequencies, showing a good agreement with each other. The assignment of the vibration modes are based on the theoretically calculated frequencies through Gaussian procedure.

On other hand, we have assigned the ${ }^{1} \mathrm{H}-\mathrm{NMR}$ and ${ }^{13} \mathrm{C}-\mathrm{NMR}$ spectroscopic data (Fig. S5S12), using routine 2D methods and they are consistent with the proposed structures.

In ${ }^{1} \mathrm{H}-\mathrm{NMR}$ spectra for 2-stpy and 2-qtpy ligands, the position of $\mathrm{N}$-donor atoms gives rise to corresponding ${ }^{1} \mathrm{H}$-splitting pattern of the 2,2'-6',2"-terpyridine domain (AB-Pattern for protons $\mathrm{H}^{\mathrm{A} 1}, \mathrm{H}^{\mathrm{A} 4}, \mathrm{H}^{\mathrm{B} 2}, \mathrm{H}^{\mathrm{A} 3}$ and $\mathrm{H}^{\mathrm{A} 2}$, with chemical shift at $\delta \sim 8.73,8.70,8.60,7.90$ and 7.40 ppm, respectively).

In the same way, for 3-qtpy and 4-stpy ligands, the position of $\mathrm{N}$-donor atoms gives rise to corresponding ${ }^{1} \mathrm{H}$-splitting pattern of the 3,2'-6',3" and 4,2'-6',4"-terpyridine domain, respectively. For 3-qtpy the AB-Pattern for protons $\mathrm{H}^{\mathrm{A} 1}, \mathrm{H}^{\mathrm{A} 2}, \mathrm{H}^{\mathrm{A} 4}, \mathrm{H}^{\mathrm{B} 2}$ and $\mathrm{H}^{\mathrm{A} 3}$ exhibit chemical shifts at $\delta=9.39,8.72,8.53,7.92$ and $7.49 \mathrm{ppm}$ respectively and for 4-stpy the AB-Pattern doublets for protons $\mathrm{H}^{\mathrm{A} 1}, \mathrm{H}^{\mathrm{A} 2}$ and $\mathrm{H}^{\mathrm{B} 2}$ are observed with chemical shift, approximately at $\delta=8.80,8.00$ and $7.90 \mathrm{ppm}$.

Interestingly, the signals of $\mathrm{H}^{\mathrm{B} 2}$ in 2-stpy and 2-qtpy ligands are downfield shifted compared to those of 3-qtpy and 4-stpy, indicating that the electron density of $\mathrm{H}^{\mathrm{B} 2}$ in 2stpy and 2-qtpy is less than that of 3-qtpy and 4-stpy. A possible explanation is that, due to the change in the $\mathrm{N}$-position from 2- to 3- or 4-in the tpy moiety, intramolecular C-H $\cdots \mathrm{N}$ contacts are formed in 2,2'-6',2"-terpyridine (with a trans-trans arrangement) minimizing the steric hindrance of hydrogen atoms. ${ }^{9}$ These intramolecular short contacts are confirmed by the crystal structure of 2-stpy (see below).

As expected, the change of substituent gives rise to the corresponding signals for thienyl and quinolinyl groups. All protons can be readily distinguished using COSY and HSQC experiments.

In order to confirm the spectroscopic data, a DFT/GIAO approach has been used to calculate the ${ }^{13} \mathrm{C}$ chemical shifts. This methodology has been used for NMR assignments in several natural products. ${ }^{37-39}$ The combined approach of extensive spectroscopic analysis and quantum mechanical methods has been used for the reassignment of structures, ${ }^{40}$ and 
can be very helpful to either confirm or discard both rigid and flexible molecular structures. $^{41,42}$

The differences between theoretical and experimental values $\Delta \delta=\mid \delta \exp -\delta$ calc $\mid$ show a measure of the dispersion between the theoretical and experimental chemical shift values for compounds (Table S3). Our results show that GIAO/DFT calculations on the optimized structure at the mPW1PW91/6-31G(d,p) level of theory provide excellent results that are in agreement with experimental values for ${ }^{13} \mathrm{C}$ chemical. Therefore, these values confirm and support the experimentally derived assignments of all compounds.

Moreover, it is also interesting to note that 2-stpy, 4-stpy, 3-qtpy and 2-qtpy are soluble in solvents as $\mathrm{CHCl}_{3}, \mathrm{CH}_{2} \mathrm{Cl}_{2}$ and slightly soluble in $\mathrm{EtOH}$.

\subsection{Structural Description of 2-stpy}

The 2-stpy ligand crystallizes in the centrosymmetric space group $\mathrm{P} 2{ }_{1} / \mathrm{n}$. Fig. 1 presents the ellipsoid plots, showing the labeling scheme used. The terpyridine unit is slightly twisted, with angles of $0.55(10)$ and $15.04(9)^{\circ}$ between the planes of the rings containing pairs of atoms N1/N2 and N2/N3 respectively (Fig 1. left), being the pyridine ring containing N3 significantly rotated with respect to the central one (N2) (Fig 1. right). The main distortion concerns the dihedral angle subtended by the thienyl substituent, rotated in turn by $47.10(9)^{\circ}$ out of the plane of the pyridine central ring (N2). The external pyridine rings reveal a trans-trans arrangement, which minimizes the electrostatic interactions between the nitrogen lone pairs in the $2,2^{\prime}: 6^{\prime}, 2^{\prime \prime}$-terpyridine, allowing the formation of intramolecular H-bonds between $\mathrm{C} 10-\mathrm{H} 10 \cdots \mathrm{N} 1$ atoms. $^{9}$

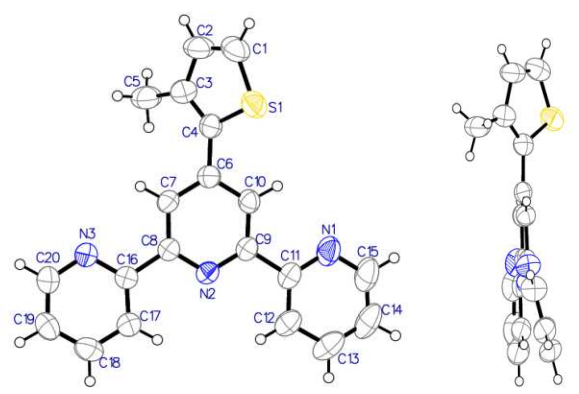

Fig. 1 Left side: the molecular structure of 2-stpy; the thermal ellipsoids are drawn at the $50 \%$ probability level. Right side: the lateral projection indicates the large torsion angle between the central pyridyl ring and the thienyl substituent. 
The most interesting aspect of this structure resides in its supramolecular nature, driven by two types of relevant interactions, fulfilling a quite different role each. They are presented in Table S4 $\left(\pi \cdots \pi\right.$-contacts) and Table S5 $\left(\mathrm{C}-\mathrm{H} \cdots \pi\right.$ interactions). ${ }^{43}$ The $\pi-\pi$ interactions are given between the pyridyl rings of the tpy moiety (containing N1/N2), linking the molecules in dimers projected down along the (010) direction. (Fig 2, left)

These units are interconnected by $\mathrm{C}-\mathrm{H} \cdots \pi$ bonds involving $\mathrm{H} 5 \mathrm{C}$ (almost vertical in the figure) and the pyridine ring (N3), linking the dimers into a broad 2D structure parallel to (100). (Fig. 2, right)

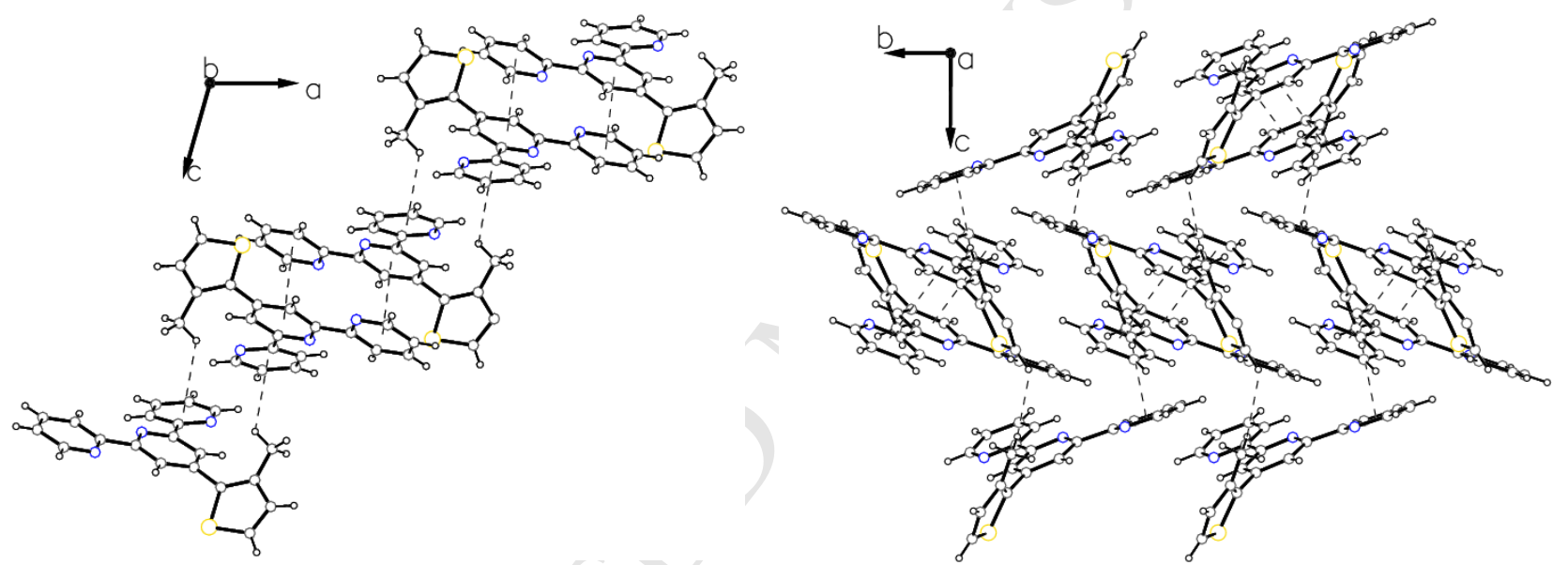

Fig. 2. Packing view of 2-stpy. Projection along the (010) (left) and (100) (right) directions, showing the full structure build up by $\mathrm{C}-\mathrm{H} \cdots \pi$ and $\pi \cdots \pi$-contacts.

\subsection{TG Analysis}

These compounds are thought to be precursors of coordination compounds, the synthesis of which is carried out through solvothermal techniques under temperatures reaching up to $200{ }^{\circ} \mathrm{C}$. It becomes then, very important to know their thermal stability. For this, thermogravimetric analyses were performed in the $30-550{ }^{\circ} \mathrm{C}$ range at a heating rate of $10^{\circ} \mathrm{C} \min ^{-1}$. Fig. S13 shows the TGA curves for terpyridine ligands. It can be observed that the ligands are stable up to $280^{\circ} \mathrm{C}$; subsequent to this, the ligands exhibit a rapid weightloss process around $360^{\circ} \mathrm{C}$ for stpy ligands (2-stpy and 4-stpy ) and $390{ }^{\circ} \mathrm{C}$ for qtpy (3- 
qtpy and 2-qtpy), corresponding to the decomposition process of the organic ligands. These results show that all ligands display an excellent thermal stability.

\subsection{Electronic absorption spectra}

The absorption properties for these ligands have been investigated in $\mathrm{CH}_{2} \mathrm{Cl}_{2}$ solutions. The absorption spectra are shown in Fig. 3 and their absorption band maxima and molar extinction coefficients are listed in Table 1. All spectra show absorption bands below 400 $\mathrm{nm}$. For 2-stpy a well-defined broad absorption band, with two maxima centered at $264 \mathrm{~nm}$ and $292 \mathrm{~nm}$, can be seen, while the 4-stpy ligand shows a band centered at $272 \mathrm{~nm}$ with a shoulder at $307 \mathrm{~nm}$. The quinolinyl tpy ligands, exhibit a less structured absorption band with two shoulders: at $263 \mathrm{~nm}$ and $315 \mathrm{~nm}$ for 3-qpty and $286 \mathrm{~nm}$ and $315 \mathrm{~nm}$ for 2-qtpy. The absorption maxima are independent of solvent polarity; the comparison with the spectral features of the pure ligands in solution, allows us to postulate that the electron transition involved has a $\pi \rightarrow \pi^{*}$ character. $^{8,}{ }^{15}$ In this case, the lowest energy $\pi \rightarrow \pi^{*}$ absorption bands of these ligands were very similar (shifting less than $25 \mathrm{~nm}$ ). Therefore, the substitution of relatively weak electron donating or withdrawing groups, such as quinoline and thiophene rings, showed only a small effect on the absorption maxima.
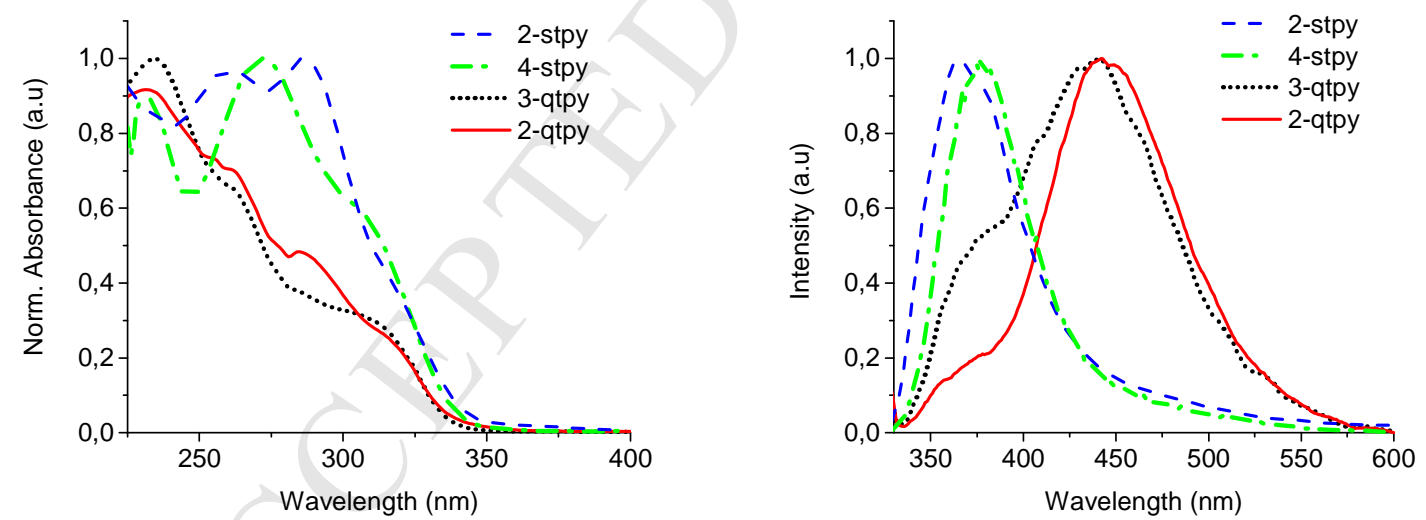

Fig. 3. Absorption (left) and Emission (right) spectra of terpyridine ligands in $\mathrm{CH}_{2} \mathrm{Cl}_{2}$ solution.

Table 1. Summary of spectroscopic characterization of terpyridine ligands

\begin{tabular}{cc|ccc}
\hline \multicolumn{3}{c}{ Absorption } & Emission \\
\hline Ligand & $\lambda_{\max (\mathrm{nm})}^{\text {Abs }}\left(\varepsilon / 10^{3} \mathrm{M}^{-1} \mathrm{~cm}^{-1}\right)$ & $\lambda_{\max }^{E m}(\mathrm{~nm}){ }^{\mathrm{b}}$ & Stokes shift $\left(\mathrm{cm}^{-1}\right)$ & $\lambda_{\max }^{E m}(\mathrm{~nm})^{\mathrm{c}}$ \\
\hline
\end{tabular}




\begin{tabular}{cc|ccc}
\hline 3-qtpy & $263(32.3)$ & 438 & 8915 & 378 \\
& $315(13.9)$ & & & 384,532 \\
\hline 2-qtpy & $286(12.3)$ & 446 & 9325 & 395 \\
& $315(6.30)$ & & & \\
\hline 4-stpy & $272(33.5)^{\mathbf{d}}$ & $378^{\mathbf{d}}$ & 6118 & 413,550 \\
& $307(18.6)^{\mathbf{d}}$ & & & 5546 \\
\hline 2-stpy & $264(26.8)$ & 370 & & \\
& $292(27.2)$ & & & \\
\hline
\end{tabular}

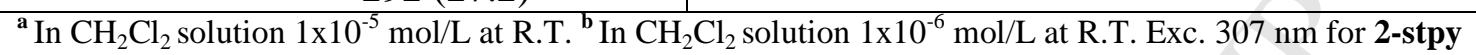
and $315 \mathrm{~nm}$ for 3-qtpy and 2-qtpy ${ }^{\mathrm{c}}$ Emission in solid state. Exc. $307 \mathrm{~nm}$ for 2-stpy and 4-stpy. Exc. 315 $\mathrm{nm}$ for 3-qtpy and 2-qtpy. ${ }^{\mathrm{d}}$ Ref. 13.

\subsection{Fluorescence in $\mathrm{CH}_{2} \mathrm{Cl}_{2}$ solution and Solid state}

The representative normalized emission in $\mathrm{CH}_{2} \mathrm{Cl}_{2}$ solutions are shown in Fig. 3, right. After excitation at $307 \mathrm{~nm}$ for 2-stpy and 4-stpy and $315 \mathrm{~nm}$ for 3-qtpy and 2qtpy ligands, emission bands can be appreciated at 370, 378, 438 and $446 \mathrm{~nm}$ for 2-stpy, 4-stpy, 3-qtpy and 2-qtpy respectively. (Table 1). The short Stockes shifts can be explained due to the $\pi \rightarrow \pi^{*}$ intramolecular fluorescence.

Due to the change of substituent, significant differences in the fluorescence behavior can be appreciated; 2-stpy and 4-stpy appear in a higher energy region compared to 3-qtpy and 2qtpy; and there is no marked difference in the fluorescence maximum wavelength between 3-qtpy and 2-qtpy.

In solid state, the emission of the tpy derivatives (Fig. 4) is found to be completely different from their emission in solution phase. The difference in the emission bands in the solid powder is attributed to aggregate emission. Interestingly, the emission of 3-qtpy and 2-qtpy ligand are blue shifted $60 \mathrm{~nm}$ with regard to their solution phase spectrum, while in 2-stpy and 4-stpy the emission bands are $43 \mathrm{~nm}$ and $17 \mathrm{~nm}$ red shifted from the corresponding solution phase spectrum. Additionally, the 2-qtpy and 2-stpy ligands exhibit an excimer-like emission with a maximum at $532 \mathrm{~nm}$ and $550 \mathrm{~nm}$, respectively, as also reported in some 2-tpy derivatives. ${ }^{9}$

In solid state, other factors such as structural parameters (e.g. torsion angles) and intermolecular interactions, play a crucial role in the emission properties. Therefore, the shifts changes of the emission maxima in the quinolinyl and thienyl tpy ligands are expected to be due to different crystalline arrangements of the molecules and consequent 
intermolecular interactions at the global level of the system. However, in order to find a structural relationship that explains the luminescence phenomenon, it is necessary to conduct thorough studies involving a larger number of experiences and measurements.

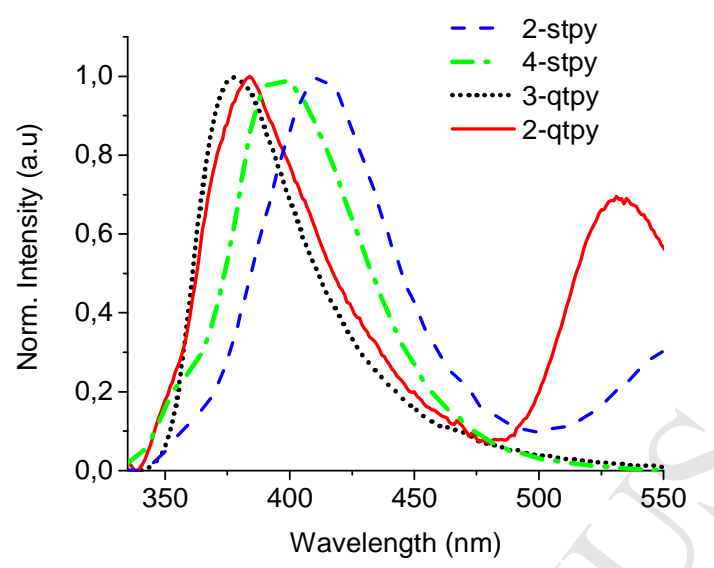

Fig. 4. Emission spectra of terpyridine ligands in solid state

\subsection{Density Functional calculations. DFT and TD-DFT}

For a better understanding of the photophysical properties of terpyridine ligands, density functional calculations of the frontier molecular orbitals were performed in order to gain insight into the nature of the ground electronic state.

DFT calculations were used to optimize the geometry in gas phase of tpy ligands in ground-state. In the particular case of the compound 2-stpy, whose molecular structure was determinated by X-Ray diffraction and informed here, Table S6 shows a very close agreement between the experimental and DFT-optimized structural data. It should be noted that when comparing this theoretical structure (optimized in gas phase, without restrictions) with the real structure in solid phase (which undergoes reticular constraints), important differences in dihedral angles will be observed: that is the dihedral angles of pyridine rings. TD-DFT calculations allowed us to compute absorption spectra for terpyridine ligands over the basis of the ground-state optimized geometry and considering the solvent influence. Fig. 5 shows the computed absorption spectra in close agreement with the experimental ones. Theoretical TD-DFT results, Table 2, support the nature of the absorption as $\pi \rightarrow \pi^{*}$, and adds the information that correspond to intramolecular charge transfer. This is consistent with their UV-vis absorption assignments. 
The calculated HOMO-LUMO (band gaps, $\mathbf{E}_{\mathbf{g}}^{\text {Calc }}$ ) (Table 3) and the highest occupied molecular orbital (HOMO and HOMO-1) and lowest unoccupied molecular orbital (LUMO and LUMO+1), of these terpyridine ligands (Fig. 6.), are affected by the substituents and the N-position in the tpy moiety.

For thienyl tpy ligands, the $\pi$-electrons in the HOMO of 2-stpy and 4-stpy are localized mainly over the thienyl substituent (can be denoted as: $\pi_{\mathrm{s}}$ ), while their LUMOs are localized only on the tpy moiety (denoted as: $\pi_{\text {tpy }}$ ).

In the case of quinolinyl tpy ligands, the electron density in HOMO is localized mainly on the tpy unit in 3-qtpy (denoted as: $\pi_{\text {tpy }}$ ) and over the entire molecule in 2-qtpy (denoted as: $\pi_{\text {tpy }} / \pi_{\mathbf{q}}$ ), while their LUMOs are mainly delocalized on the central pyridine ring and quinolinyl ring $\left(\pi_{\mathrm{py}} / \pi_{\mathbf{q}}\right)$.

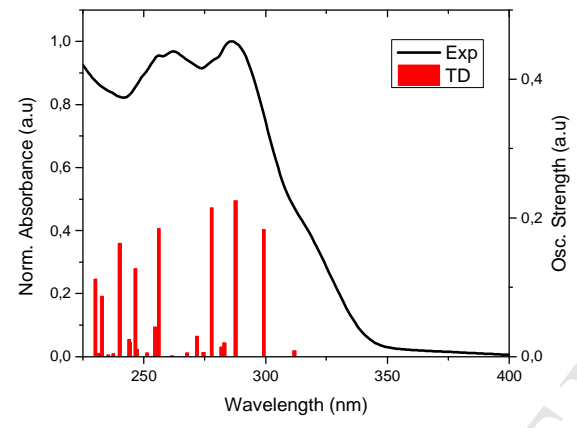

a)

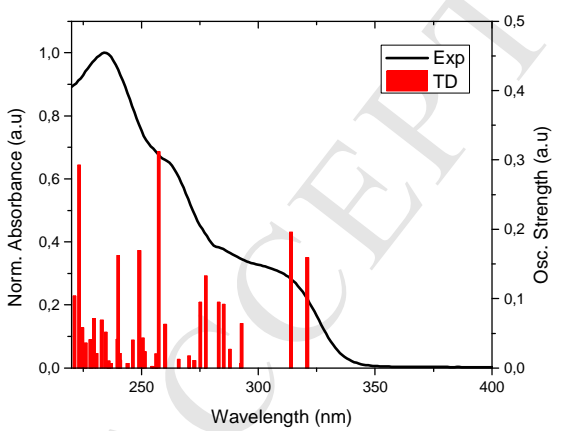

c)

Fig. 5. TD-DFT computed and experimental absorption spectra in $\mathrm{CH}_{2} \mathrm{Cl}_{2}$ for a) 2-stpy, b) 4-stpy, c) 3-qtpy and d) 2-qtpy ligands.

On the other hand, the calculated energy values, $\mathrm{E}_{\mathrm{g}}^{\text {Calc }}$, support that the substituents have a direct effect on the energy of the frontier molecular orbitals. The thienyl substituent in 4- 
stpy and 2-stpy increases the HOMO-LUMO gap in comparison with the quinolinyl-tpy ligands (3-qtpy and 2-qtpy).

Moreover, the change in the N-position from 2- to 3-qtpy modifies the electronic density distribution on the HOMO and/or LUMO, which affect the electron mobility and also the energy of the frontier molecular orbitals. As a result, these isomers can be present differences in the shift of the absorption and emission bands.

Finally, the theoretical and experimental results demonstrate that both, aryl substituents and the $\mathrm{N}$-position in the external pyridine ring, constitute a key factor in the photophysical properties of these ligands.

Table 2. Summary of the main energy $(\mathbf{E})$, wavelength $(\boldsymbol{\lambda})$ and oscillator strength $(\boldsymbol{f})$, computed for observed transitions (N) in the absorption spectra of terpyridine ligands, together with the orbitals implied.

\begin{tabular}{|c|c|c|c|c|c|}
\hline Comp. & $\mathbf{N}$ & $\mathbf{E} / \mathbf{e V}$ & $\bar{V}$ & $\lambda / \mathbf{n m} f$ & Major Contributions \\
\hline \multirow{4}{*}{ 3-qtpy } & 1 & 3.86 & 320 & 0.16 & HOMO $\rightarrow$ LUMO (87\%), H-1 $\rightarrow$ LUMO (8\%) \\
\hline & 2 & 3.95 & 313 & 0.19 & $\mathrm{H}-1 \rightarrow \mathrm{LUMO}(86 \%), \mathrm{HOMO} \rightarrow \mathrm{LUMO}(9 \%)$ \\
\hline & 8 & 4.47 & 277 & 0.13 & $\mathrm{H}-3 \rightarrow \mathrm{L}+1(14 \%), \mathrm{H}-1 \rightarrow \mathrm{L}+2(19 \%), \mathrm{HOMO} \rightarrow \mathrm{L}+2(33 \%), \mathrm{H}-2 \rightarrow \mathrm{L}+1(4 \%)$ \\
\hline & 14 & 4.82 & 257 & 0.31 & $\mathrm{H}-4 \rightarrow \mathrm{L}+1(44 \%), \mathrm{H}-3 \rightarrow \mathrm{L}+1(11 \%), \mathrm{H}-2 \rightarrow \mathrm{L}+1(7 \%), \mathrm{H}-1 \rightarrow \mathrm{L}+3(7 \%)$ \\
\hline \multirow{4}{*}{ 2-qtpy } & 1 & 3.94 & 314 & 0.19 & HOMO $\rightarrow$ LUMO $(95 \%)$ \\
\hline & 2 & 4.08 & 303 & 0.15 & $\mathrm{H}-1 \rightarrow \mathrm{LUMO}(91 \%), \mathrm{HOMO} \rightarrow \mathrm{L}+1(3 \%)$ \\
\hline & 11 & 4.67 & 265 & 0.19 & $\mathrm{H}-1 \rightarrow \mathrm{L}+1(55 \%), \mathrm{HOMO} \rightarrow \mathrm{L}+2(23 \%), \mathrm{H}-7 \rightarrow \mathrm{L}+1(5 \%), \mathrm{H}-6 \rightarrow \mathrm{L}+1(2 \%)$ \\
\hline & 16 & 4.94 & 251 & 0.20 & $\mathrm{H}-5 \rightarrow \mathrm{L}+1(41 \%), \mathrm{H}-3 \rightarrow \mathrm{L}+1(30 \%), \mathrm{H}-1 \rightarrow \mathrm{L}+4(10 \%)$ \\
\hline \multirow{4}{*}{ 4-stpy } & 2 & 3.86 & 321 & 0.33 & HOMO $\rightarrow$ LUMO $(91 \%)$, HOMO $\rightarrow$ LUMO+1 (6\%) \\
\hline & 3 & 4.25 & 291 & 0.32 & $\mathrm{H}-1 \rightarrow \mathrm{LUMO}(81 \%), \mathrm{H}-7 \rightarrow \mathrm{LUMO}(3 \%), \mathrm{H}-2 \rightarrow \mathrm{L}+1(2 \%), \mathrm{HOMO} \rightarrow \mathrm{L}+1(8 \%)$ \\
\hline & 9 & 4.51 & 275 & 0.25 & $\mathrm{H}-2 \rightarrow \mathrm{L}+1(31 \%), \mathrm{H}-1 \rightarrow \mathrm{L}+1(45 \%), \mathrm{H}-7 \rightarrow \mathrm{L}+1(9 \%), \mathrm{H}-5 \rightarrow \mathrm{LUMO}(2 \%), \mathrm{H}-3 \rightarrow \mathrm{L}+1(4 \%)$ \\
\hline & 14 & 4.87 & 255 & 0.11 & HOMO $\rightarrow$ LUMO+2 (75\%), H-5 $\rightarrow$ LUMO $(6 \%)$ \\
\hline \multirow{5}{*}{ 2-stpy } & 1 & 3.98 & 311 & 0.01 & $\mathrm{H}-1 \rightarrow \mathrm{L}+1(10 \%), \mathrm{HOMO} \rightarrow \mathrm{LUMO}(53 \%), \mathrm{HOMO} \rightarrow \mathrm{L}+1(26 \%)$ \\
\hline & 2 & 4.14 & 299 & 0.18 & $\mathrm{HOMO} \rightarrow \mathrm{LUMO}(36 \%), \mathrm{HOMO} \rightarrow \mathrm{L}+1(60 \%)$ \\
\hline & 3 & 4.31 & 288 & 0.22 & $\mathrm{H}-1 \rightarrow \mathrm{LUMO}(39 \%), \mathrm{H}-1 \rightarrow \mathrm{L}+1(27 \%), \mathrm{HOMO} \rightarrow \mathrm{L}+1(12 \%)$ \\
\hline & 6 & 4.46 & 277 & 0.21 & $\mathrm{H}-1 \rightarrow \mathrm{LUMO}(39 \%), \mathrm{H}-1 \rightarrow \mathrm{L}+1(53 \%)$ \\
\hline & 11 & 4.84 & 256 & 0.18 & H-4->LUMO (12\%), H-1->L+2 (61\%), HOMO->L+2 (8\%) \\
\hline
\end{tabular}


Table 3. Theoretically energy values for tpy ligands.

\begin{tabular}{lccc}
\hline Compd. & \multicolumn{3}{c}{ Energy (eV) } \\
\cline { 2 - 4 } & LUMO & HOMO & $\mathbf{E}_{\mathbf{g}}^{\text {Calc }}$ \\
\hline 2-stpy & -1.64 & -6.26 & 4.62 \\
4-stpy & $-1,90$ & $-6,40$ & 4,50 \\
3-qtpy & $-2,24$ & $-6,66$ & 4,42 \\
2-qtpy & $-2,18$ & $-6,66$ & 4,48 \\
\hline
\end{tabular}
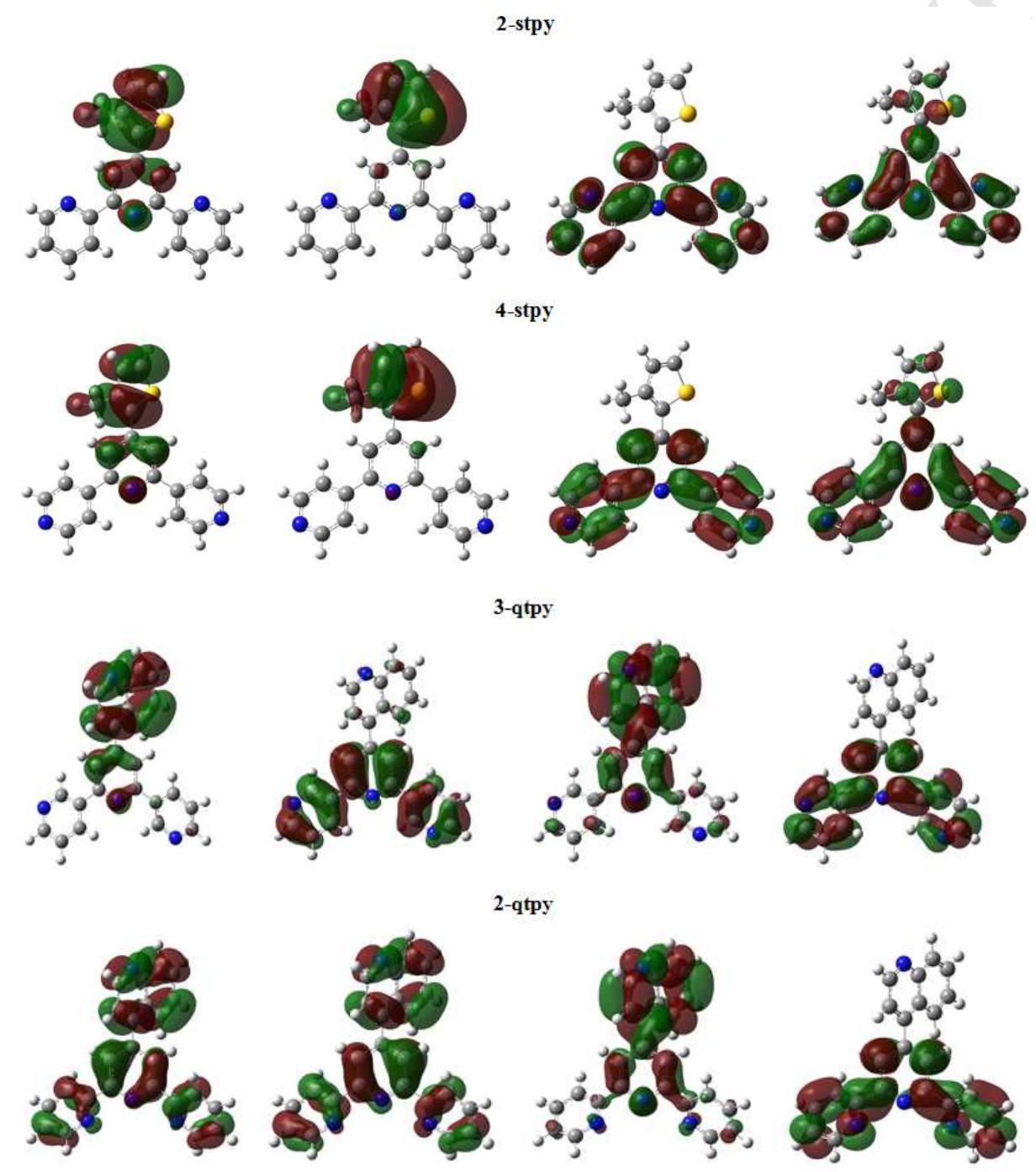

Fig. 6. DFT computed frontier orbitals for terpyridine ligands. From left to right: HOMO-1, HOMO, LUMO and LUMO+1 plots.

\subsection{Electrochemical behaviour}


The electrochemical behavior of the tpy ligands was studied by cyclic voltammetry in anhydrous dichloromethane with tetrabutylammonium tetrafluorborate $\left(\mathrm{TBABF}_{4}\right)$ as electrolyte support.

All molecules show an irreversible behavior, both in the anodic and cathodic scans; nevertheless, in the anodic scan two molecules 2-stpy and 2-qtpy show well-defined anodic peaks (figures 7-8). In the other cases, 4-stpy and 3-qtpy only a shoulder can be seen. Furthermore, the oxidation peak current shows a remarkable decrease during the successive cyclic voltammetric sweeps. This phenomenon can be attributed to the consumption of absorbed ligand (and/or its oxidation product) on the electrode surface. ${ }^{44}$ In the return scan, a reduction peak is observed only for 2-qtpy and 4-stpy, that is it can be assigned to an electrochemical reduction of $\mathrm{L}^{*+}$ or $\mathrm{L}^{+}$.

As shown in the anodic profile, the cathodic scan shows irreversible waves in all cases, but when the electrode potential is increased to more negative potentials, an exponential current appears. ${ }^{45}$ In all cases, the first anodic and cathodic peak are very sensitive to the scan rate since both move to more anodic or more cathodic potentials, respectively, when the scan rate increases. The electrochemical data (anodic and cathodic peaks potentials $\left(\mathrm{E}_{\mathrm{ap}}, \mathrm{E}_{\mathrm{cp}}\right)$, and anodic and cathodic peaks currents $\left(i_{\text {ap }}, i_{c p}\right)$ ) are summarized in table 4.

Table 4. Electrochemical parameters obtained through cyclic voltammetry at $100 \mathrm{mV} / \mathrm{s}$ scan rate.

\begin{tabular}{cccc|c|c|cc}
\hline Ligand & $\mathbf{E}_{\mathbf{a p}} / \mathbf{V}$ & $\mathbf{i}_{\mathbf{a p}} / \mathbf{m A}$ & $\mathbf{E}_{\mathbf{c p}} / \mathbf{V}$ & $\mathbf{E}_{\mathbf{a p}}-\mathbf{E}_{\mathbf{a p} / 2} \mid / \mathbf{m V}$ & $\mathbf{E}_{\mathbf{c p}}-\mathbf{E}_{\mathbf{c p} / 2} \mid / \mathbf{m V}$ & $\mathbf{i}_{\mathbf{c p}} / \mathbf{m A}$ \\
\hline 2-stpy & 1,370 & $1,20 \times 10^{-2}$ & $-1,300$ & 135 & - & $-1,92 \times 10^{-2}$ \\
4-stpy & - & - & $-1,000$ & - & 125 & $-1,96 \times 10^{-2}$ \\
3-qtpy & - & - & $-0,906$ & - & 102 & $-1,21 \times 10^{-2}$ \\
2-qtpy & 2,100 & $3,94 \times 10^{-2}$ & $-0,935$ & 130 & - & $-1,74 \times 10^{-2}$ \\
\hline
\end{tabular}

By relating the LUMO values to the reduction potentials, a correspondence may be found, ${ }^{25}$ since the presence of thienyl groups displaces the ligand reduction potential towards more cathodic values than the ligands possessing quinolinyl groups.

According to HOMO-LUMO levels maps, it is possible to propose that, in the case of 2stpy and 4-stpy ligands, the oxidation process occurs mainly in the thienyl substituent. For 
the 3-qtpy ligand the oxidation process occurs in both terpirydine and quinolyne groups, while for 2-qtpy the oxidation process occurs mainly in terpyridine moiety.

On the other hand, the reduction processes of 2-stpy and 4-stpy ligands involve the terpirydine groups, whereas the 2-qtpy and 3-qtpy ligands mainly involve the quinoline ring.

Electrochemical features of terpyridines have been reported in the literature, showing one electron reduction process in the cyclic voltammograms. ${ }^{46}$ In other studies a second electron transfer process can be seen. ${ }^{47}$ The large peak observed beyond $-2,2 \mathrm{~V}$ could be assigned to an irreversible multielectron reduction. ${ }^{46}$
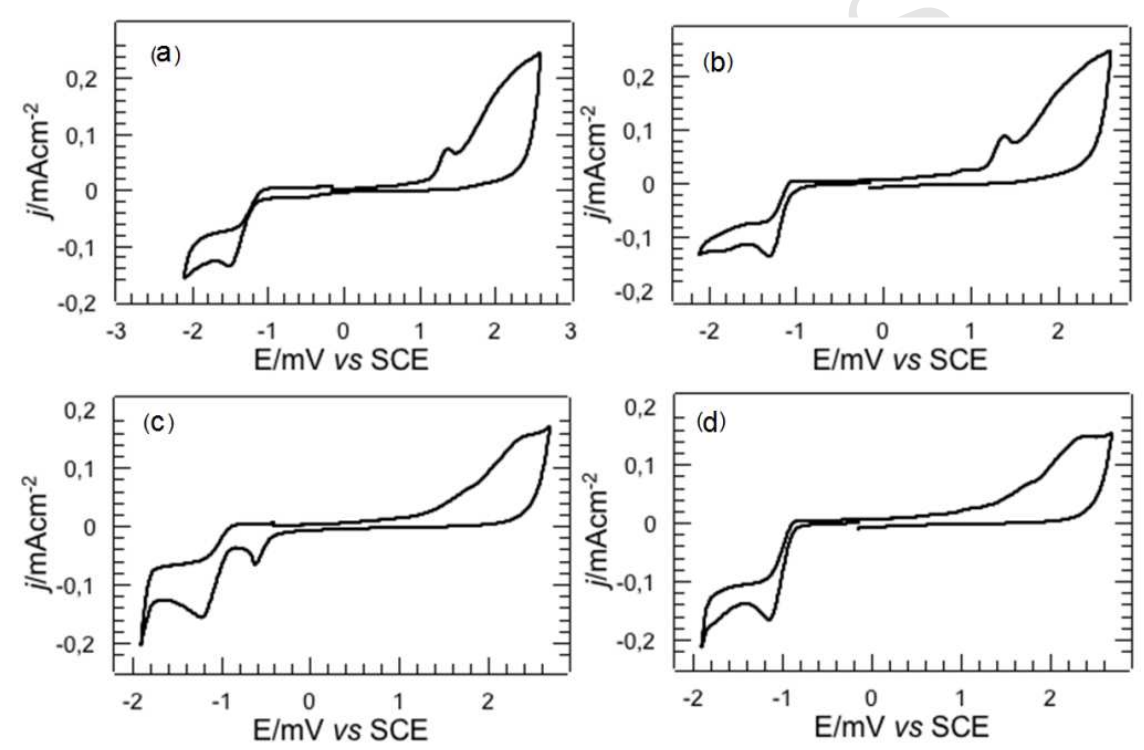

Fig. 7. Anodic and cathodic voltammograms of 2-stpy (a, b) and 4-stpy (c, d) ligands respectively. Conditions: glassy carbon electrode, ligand $[0,1 \mathrm{M}]$ in dichloromethane with $\mathrm{TBABF}_{4}[0,1 \mathrm{M}]$ at $100 \mathrm{mV} / \mathrm{s}$ scan rate. 

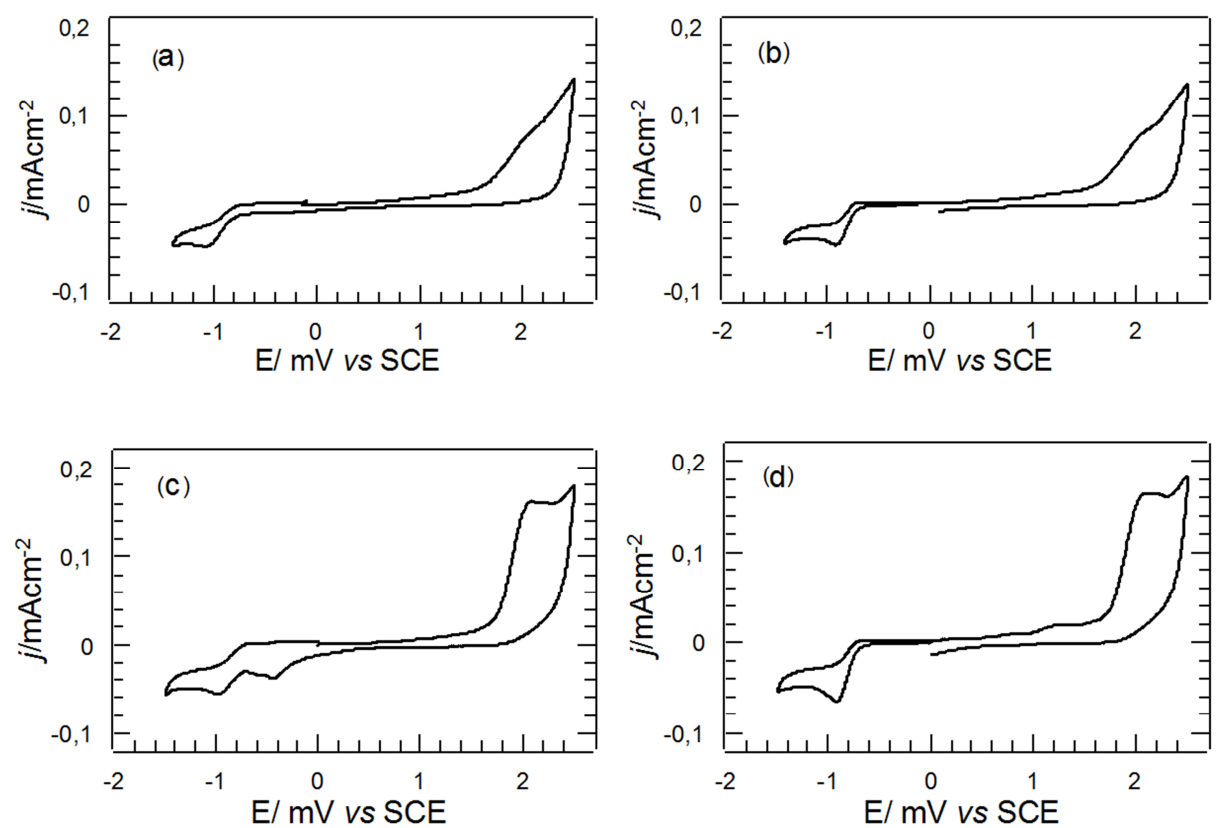

Fig. 8. Anodic and cathodic voltammograms of 2-qtpy (a, b) and 3-qtpy (c, d) ligands respectively. Conditions: glassy carbon electrode, ligand $[0,1 \mathrm{M}]$ in dichloromethane with $\mathrm{TBABF}_{4}[0,1 \mathrm{M}]$ at $100 \mathrm{mV} / \mathrm{s}$ scan rate.

\section{Conclusions}

Four terpyridine ligands derivatives containing different aryl subtituents were synthesized and their photophysical properties were investigated systematically in solution and solid state. The IR and NMR spectroscopy studies are in agreement with the molecular structures proposed for all tpy ligands; this has been corroborated through theoretical DFT calculations. All compounds exhibit excellent thermal stability (up to $280^{\circ} \mathrm{C}$ ). The absorption spectra in $\mathrm{CH}_{2} \mathrm{Cl}_{2}$ solution showed a small shift on the absorption maxima when changing the $\mathrm{N}$-position in the tpy moiety and the substituent of thienyl (in 2-stpy/4-stpy) to quinolinyl (in 2-qtpy/3-qtpy). On the other hand, the emission spectra in $\mathrm{CH}_{2} \mathrm{Cl}_{2}$ solution of 2-qtpy and 3-qtpy ligands showed pronounced red-shifts, in relation to 2stpy/4-stpy ligands. All ligands exhibit violet to blue $\pi-\pi^{*}$ photoluminescence. The spectroscopic studies and TD-DFT calculations demonstrate that the luminescent properties of these terpyridine derivatives can be drastically modified by different aryl substituents and N-position in the tpy moiety. The anodic and cathodic electrochemical behavior of the 
terpyridine ligands corresponds to irreversible processes. The oxidation process occurs mainly in the terpyridine and quinoline groups for 2-qtpy and 3-qtpy ligands, while in the case of 2-stpy and 4-stpy ligands the oxidation processes occur on the thienyl substituent. The reduction process of 2-qtpy and 3-qtpy ligands mainly involves the quinoline ring, whereas in the 2-stpy and 4-stpy ligands it involves the tpy moiety.

\section{Acknowledgments}

This research was performed as part of the Chilean-French International Associated Laboratory for "Inorganic Functional Materials" (LIA M3 CNRS n ${ }^{\circ} 1027$ ). Financial supports from FONDECYT (Chile), grant $\mathrm{N}^{\circ} 1130433$ and UNAB DI-773-15R (Y. Moreno), and CNRS and the Université de Rennes-1 are gratefully acknowledged. D. Toledo thanks to CONICYT (Chile) for support of graduate fellowship $\mathrm{N}^{\circ}: 21120148$ and to Gaëtan Louarn (ENSCR, France) for assistance with TGA experiments. F. Brovelli thanks to UDEC for financial support through UDEC-VRID 216.412.049-1.0. The authors acknowledge to crystalography and photochemical laboratory of UNAB.

\section{Supporting Information}

Crystallographic data for 2-stpy structure has been deposited with the Cambridge Crystallographic Data Centre as supplementary publication no. CCDC 1563848. Copies of the data can be obtained, free of charge, on application to CCDC, 12 Union Road, Cambridge CB2 1EZ, UK, (fax: +44 1223336033 or e-mail: deposit@ccdc.cam.ac.uk).

\section{References}

1. Ulrich S. Schubert, Andreas Winter and G. R. Newkome, Terpyridine-Based Materials: For Catalytic, Optoelectronic and Life Science Applications, WileyVCH, Weinheim, Germany, 2011.

2. A. Y. Robin and K. M. Fromm, Coordination Chemistry Reviews, 2006, 250, 21272157.

3. K. Banerjee and K. Biradha, Crystal Growth \& Design, 2012, 12, 4264-4274.

4. A. Wild, A. Winter, F. Schlutter and U. S. Schubert, Chemical Society Reviews, 2011, 40, 1459-1511.

5. A. Winter, G. R. Newkome and U. S. Schubert, ChemCatChem, 2011, 3, 13841406. 
6. I. Eryazici, C. N. Moorefield and G. R. Newkome, Chemical Reviews, 2008, 108, 1834-1895.

7. J. Heine, J. Schmedt auf der Günne and S. Dehnen, Journal of the American Chemical Society, 2011, 133, 10018-10021.

8. Y. Liu, J. Guo, R. Liu, Q. Wang, X. Jin, L. Ma, W. Lv, S. Liu, S. Yuan and H. Zhu, Journal of Luminescence, 2015, 157, 249-256.

9. A. Maron, A. Szlapa, T. Klemens, S. Kula, B. Machura, S. Krompiec, J. G. Malecki, A. Switlicka-Olszewska, K. Erfurt and A. Chrobok, Organic \& Biomolecular Chemistry, 2016, 14, 3793-3808.

10. C. Fan, X. Wang and J. Luo, Optical Materials, 2017, 64, 489-495.

11. G. Koyyada, P. Kumar Ch, P. Salvatori, G. Marotta, M. G. Lobello, O. Bizzarri, F. De Angelis and C. Malapaka, Inorganica Chimica Acta, 2016, 442, 158-166.

12. M. K. Nazeeruddin, A. Kay, I. Rodicio, R. Humphry-Baker, E. Mueller, P. Liska, N. Vlachopoulos and M. Graetzel, Journal of the American Chemical Society, 1993, $115,6382-6390$.

13. C. E. Housecroft, Dalton Transactions, 2014, 43, 6594-6604.

14. C. E. Housecroft, CrystEng Comm, 2015, 17, 7461-7468.

15. D. Toledo, R. Baggio, E. Freire, A. Vega, N. Pizarro and Y. Moreno, Journal of Molecular Structure, 2015, 1102, 18-24.

16. Y. M. Klein, A. Prescimone, E. C. Constable and C. E. Housecroft, Polyhedron, 2016, 103, Part A, 58-65.

17. Z. Yin, S. Zhang, S. Zheng, J. A. Golen, A. L. Rheingold and G. Zhang, Polyhedron, 2015, 101, 139-145.

18. J. Granifo, R. Gaviño, E. Freire and R. Baggio, Acta Crystallographica Section C, 2012, 68, m269-m274.

19. D. Toledo, G. Ahumada, C. Manzur, T. Roisnel, O. Peña, J.-R. Hamon, J.-Y. Pivan and Y. Moreno, Journal of Molecular Structure, 2017, 1146, 213-221.

20. T. Mutai, J.-D. Cheon, S. Arita and K. Araki, Journal of the Chemical Society, Perkin Transactions 2, 2001, DOI: 10.1039/B102685M, 1045-1050.

21. W. Goodall, K. Wild, K. J. Arm and J. A. G. Williams, Journal of the Chemical Society, Perkin Transactions 2, 2002, DOI: 10.1039/B205330F, 1669-1681.

22. J. Wang and G. S. Hanan, ChemInform, 2005, 36, 1251-1254.

23. A. Winter, A. M. J. van den Berg, R. Hoogenboom, G. Kickelbick and U. S. Schubert, Synthesis, 2006, 2006, 2873-2878.

24. D. Toledo, A. Vega, N. Pizarro, R. Baggio, O. Peña, T. Roisnel, J.-Y. Pivan and Y. Moreno, Journal of Solid State Chemistry, 2017, 253, 78-88.

25. R. Baggio, F. Brovelli, Y. Moreno, M. Pinto and J. Soto-Delgado, Journal of Molecular Structure, 2016, 1123, 1-7.

26. G. A. East and M. A. del Valle, Journal of Chemical Education, 2000, 77, 97.

27. B. Mennucci, E. Cancès and J. Tomasi, The Journal of Physical Chemistry B, 1997, 101, 10506-10517.

28. M. J. T. Frisch, G. W.; Schlegel, H. B.; Scuseria, G. E.; Robb, M. A.; Cheeseman, J. R.; Scalmani, G.; Barone, V.; Mennucci, B.; Petersson, G. A.; Nakatsuji, H.; Caricato, M.; Li, X.; Hratchian, H. P.; Izmaylov, A. F.; Bloino, J.; Zheng, G.; Sonnenberg, J. L.; Hada, M.; Ehara, M.; Toyota, K.; Fukuda, R.; Hasegawa, J.; Ishida, M.; Nakajima, T.; Honda, Y.; Kitao, O.; Nakai, H.; Vreven, T.; Montgomery, J. A., Jr.; Peralta, J. E.; Ogliaro, F.; Bearpark, M.; Heyd, J. J.; 
Brothers, E.; Kudin, K. N.; Staroverov, V. N.; Kobayashi, R.; Normand, J.; Raghavachari, K.; Rendell, A.; Burant, J. C.; Iyengar, S. S.; Tomasi, J.; Cossi, M.; Rega, N.; Millam, N. J.; Klene, M.; Knox, J. E.; Cross, J. B.; Bakken, V.; Adamo, C.; Jaramillo, J.; Gomperts, R.; Stratmann, R. E.; Yazyev, O.; Austin, A. J.; Cammi, R.; Pomelli, C.; Ochterski, J. W.; Martin, R. L.; Morokuma, K.; Zakrzewski, V. G.; Voth, G. A.; Salvador, P.; Dannenberg, J. J.; Dapprich, S.; Daniels, A. D.; Farkas, Ö.; Foresman, J. B.; Ortiz, J. V.; Cioslowski, J.; Fox, D. J. , Gaussian, Inc., Wallingford CT, 2009, vol. Revision D.01.

29. J. Svoboda, P. Štenclová, F. Uhlík, J. Zedník and J. Vohlídal, Tetrahedron, 2011, 67, 75-79.

30. G. M. Sheldrick, Acta Crystallographica. Section C, Structural Chemistry, 2015, $71,3-8$

31. O. V. Dolomanov, L. J. Bourhis, R. J. Gildea, J. A. K. Howard and H. Puschmann, Journal of Applied Crystallography, 2009, 42, 339-341.

32. A. Spek, Journal of Applied Crystallography, 2003, 36, 7-13.

33. F. Kröhnke, Synthesis, 1976, 1976, 1-24.

34. K. Nakamoto, in Infrared and Raman Spectra of Inorganic and Coordination Compounds, John Wiley \& Sons, Inc., Hoboken, New Jersey, 2008, DOI: 10.1002/9780470405888.ch1, pp. 1-273.

35. J. J. Peron, P. Saumagne and J. M. Lebas, Spectrochimica Acta Part A: Molecular Spectroscopy, 1970, 26, 1651-1666.

36. P. Molina, A. Arques and I. Cartagena, in Comprehensive Heterocyclic Chemistry III, eds. C. A. Ramsden, E. F. V. Scriven and R. J. K. Taylor, Elsevier, Oxford, 2008, DOI: http://dx.doi.org/10.1016/B978-008044992-0.00309-6, pp. 625-739.

37. J. Casanovas, A. M. Namba, R. da Silva and C. Alemán, Bioorganic Chemistry, 2005, 33, 484-492.

38. G. Bifulco, L. Gomez-Paloma and R. Riccio, Tetrahedron Letters, 2003, 44, 71377141.

39. G. V. J. da Silva and Á. C. Neto, Tetrahedron, 2005, 61, 7763-7767.

40. D. C. Braddock and H. S. Rzepa, Journal of Natural Products, 2008, 71, 728-730.

41. A. Plaza, S. Piacente, A. Perrone, A. Hamed, C. Pizza and G. Bifulco, Tetrahedron, 2004, 60, 12201-12209.

42. P. Cimino, L. Gomez-Paloma, D. Duca, R. Riccio and G. Bifulco, Magnetic Resonance in Chemistry, 2004, 42, S26-S33.

43. C. Janiak, Journal of the Chemical Society, Dalton Transactions, 2000, DOI: 10.1039/B003010O, 3885-3896.

44. K. Naik and S. Nandibewoor, American Journal of Analytical Chemistry, 2012, 3, 656-663.

45. M. C. Gimeno, J. M. López-de-Luzuriaga, E. Manso, M. Monge, M. E. Olmos, M. Rodríguez-Castillo, M.-T. Tena, D. P. Day, E. J. Lawrence and G. G. Wildgoose, Inorganic Chemistry, 2015, 54, 10667-10677.

46. M. Al-Anber, S. Vatsadze, R. Holze, H. Lang and W. R. Thiel, Dalton Transactions, 2005, DOI: 10.1039/B508314A, 3632-3637.

47. T.-Y. Dong, M.-C. Lin, S.-W. Chang, C.-C. Ho, S.-F. Lin and L. Lee, Journal of Organometallic Chemistry, 2007, 692, 2324-2333. 


\section{Highlights}

The relationship between structure and physical properties have been established for four terpyridine derivates.

The structural changes give place to redox-potential shifts, which have been calculated theoretically (DFT).

$>$ Differences in the fluorescence behavior have been detected due to change of substituent on tpy moiety, which have been studied theoretically (TD-DFT).

$>$ The molecular structure of one thienyl-terpyridine, 2-stpy, is presented. 